\title{
A ética e a estética do ato presencial
}

\section{Anelise Angeli De Carli}

Doutoranda; Universidade Federal do Rio Grande do Sul, Porto Alegre, RS, Brasil

anelisedecarli@gmail.com

MEDINA, Cremilda. Ato presencial: mistério e transformação. São Paulo: Casa da Serra, 2016.

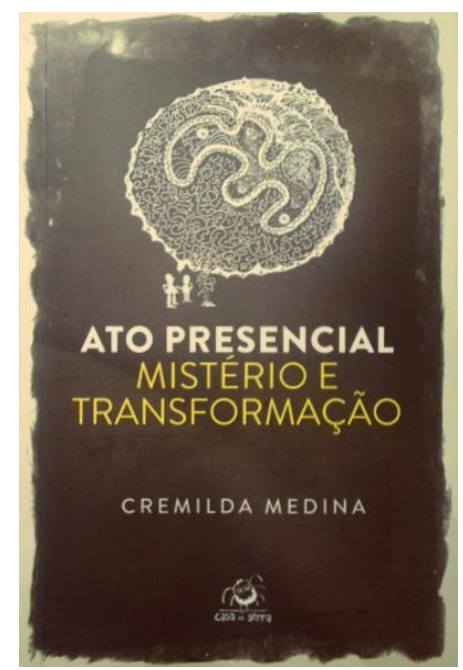

Era agosto de 2016 e esperávamos ansiosamente a mensagem que a professora Ana Taís Martins Portanova Barros enviaria avisando sobre a chegada de Cremilda e Sinval Medina à Faculdade de Biblioteconomia e Comunicação da Universidade Federal do Rio Grande do Sul (UFRGS). Esse não era um lugar qualquer: ali, os dois haviam cursado a graduação há mais de 50 anos e ainda não tinham voltado juntos como convidados. 0 nosso grupo de pesquisa, o Imaginalis, já havia tido a oportunidade de encontrá-los outras vezes, graças à ponte que desde o doutorado de Ana interligou a epistemologia complexa do Jornalismo aos Estudos do Imaginário. Mas esse, como todos os outros encontros, era especial: cada momento com ela é um ichigo-ichie ${ }^{1}$.

Neste dia, Cremilda traria para o Rio Grande do Sul o seu último título. Poucos livros escritos em primeira pessoa contam com a contribuição de tantas vozes de terceiros. A vida em coletivo não é para todos. Uma dessas pessoas é Cremilda, que, em Ato presencial, nos

${ }^{1}$ Pronúncia dos ideogramas一期一会, como explica Angelo Ishi (MEDINA, 2016, p. 121). 
coloca desde a primeira página face a face com duas de suas principais características de escrita e de pensamento: a contribuição fundamental do outro para a formação do si mesmo e a incontornável fusão entre trajetória biográfica e epistemológica. Uma série de relatos de treze ex-alunos seus ajudam a escrever a primeira parte do livro. Aos poucos, como é costume de sua literatura, vamos compreendendo que os pequenos detalhes de nossas vivências são quase ou tão importantes quanto os grandes insights teóricos que possamos produzir dentro da academia. Ela diria que é exatamente a atenção aos detalhes do cotidiano comum a condição para o acontecimento da epifania, da qual a imaginação racional não está desprevenida. Se for de outro jeito, aliás, de que serve o jornalismo?

Na primeira e maior parte do livro, a antiga aluna Ana Taís conta como a presença serena e convicta da professora acrescentava à Cremilda muitos centímetros de altura. 0 também ex-aluno Angelo Ishi utiliza um provérbio japonês para sintetizar e ampliar -como funciona paradoxalmente a metáfora - a afetação desse encontro. A própria Cremilda não se furta de buscar nos outros - quando esses mesmos não escrevem em primeira pessoa referências para pensar sobre sua própria trajetória. É por isso que o trabalho literário de seu companheiro, Sinval Medina, ganha tamanha dimensão: sua contribuição não revela somente o compartilhamento de uma jornada conjugal, mas o entendimento de que a forma também é conteúdo, e vice-versa. Ou, ainda, que toda teoria é uma ficção - e, por extensão, que toda ficção também é uma teoria. No livro também estão referenciados, com grande valor, narrativas sobre Umberto Eco, José Serra, sua última orientanda de TCC na USP, Maria Marta Corsino, e um Remulado Alves. A aproximação construída com o teórico italiano, a sintonia geracional com o político brasileiro, o trabalho sobre o transplante de órgãos e a conversa com o rapaz do Higienópolis paulistano, ganham, todas, o mesmo grau de importância. Esse último personagem, apelidado Remo, foi um dos sujeitos em pesquisa ${ }^{2}$ da tese de Cremilda de 1986.

No entanto, é, sobretudo a escolha de Cremilda de mostrar suas idéias em uma narrativa escrita em primeira pessoa, o que ainda choca os mais incautos. Acostumados que estamos a nos engajar na decifração de textos escritos ao sabor das abstrações acadêmicas, a autora - que nunca deixou de ser jornalista - faz uma opção estética e ética. A fórmula memorialística foi a estratégia adotada também em seus últimos livros Casas da viagem (2012) e Atravessagem (2014). Engajando-se na construção de uma teoria na primeira

\footnotetext{
2 Valho-me, aqui, do mesmo recurso gráfico utilizado por Ana Tais Martins Portanova Barros em sua contribuição para o livro em questão, que grifou em itálico algumas das dezenas de termos que Cremilda utiliza em sua vasta obra.
} 
pessoa do singular, na escrita de uma autobiografia como percurso do pensamento, Cremilda encoraja a desinibição da fala em primeira pessoa, forma de expressão da qual fugimos por rigor estilístico, por mais que seja através dela que pensemos. Na prática jornalística e, muitas vezes, na acadêmica, a primeira pessoa se traveste de terceira. Mas este apagamento dos sujeitos, a começar pelo si mesmo, não é um mero problema de técnica narrativa, é uma questão de visão de mundo. A própria teoria de Cremilda a explica: "0 modo de ser se traduz no modo de dizer." (MEDINA, 2016, p. 50).

Das histórias contadas por ela ou por seus companheiros de jornada tiramos ideias importantes para a prática da pesquisa e do jornalismo. Como podemos falar do intrincado entre interpretação e observação se separamos a parte empírica da parte teórica em um trabalho? Como nos entregarmos à presença atenta do outro se aprendemos a depender de um gravador ou de um caderno para lembrar os detalhes da entrevista que nos foi concedida? Para ela, num traço fenomenológico evidente, as nossas histórias, que são as mais banais possíveis, são também as mais preciosas. A transformação causada pelo compartilhamento das pequenas grandes coisas, como a presença, é um mistério a ser preservado, mesmo que nenhuma luz esclarecedora demais seja capaz de iluminar cada uma de suas sombras. Caso fosse, estaríamos fadados à reprodução do mesmo, à tecnologização do afeto, a crer na desimportância da vida cotidiana e nuclear.

A defesa das coisas desimportantes tem retomado lugar de destaque no pensamento contemporâneo frente à crescente onda de estímulo à eficiência e à eficácia da visão de mundo empresarial. Na aula magna de abertura do ano letivo da UFRGS, em março de 2016, Nuccio Ordine repetiu reiteradamente a pergunta "Para que serve?". Assim, o filósofo italiano explicou porque em épocas de crise econômica é necessário defender com unhas e dentes o que tem valor por só ser, em outras palavras, defender a cultura. É nela que resistem os valores de um povo, é dela que se alimenta o espírito, ela é o assento da cidadania e da humanidade (ORDINE, 2016).

Não se furtando de gerar uma boa polêmica no ambiente comunicológico contemporâneo, neste livro, frente a uma demagogia da comunicabilidade em época de hiperconexão, Cremilda se engaja na defesa do “[...] ato presencial diante da abstração do pensar à distância" (MEDINA, 2016, p. 25). A ideia sugere que a compressão emerge não somente do exercício de uma racionalidade lógico-analítica, mas também da ativação dos cinco sentidos. $O$ ato presencial chama os sentidos à ação, na esteira do pensamento do psiquiatra naturalizado colombiano Luis Carlos Restrepo (1998). Como a autora bem 
pontua, uma necessária racionalidade complexa é fruto justamente de uma união entre a intuição sensível à racionalidade lógico-analítica. Em tempos onde quase tudo pode ser feito remotamente, sem condenar os avanços importantes das tecnologias da informação, Cremilda embarca na viagem em defesa do estar junto.

Na comunicação mediada, os silêncios, que também significam, são desprezados. Há um enfoque somente no sentido que é manifesto. Com Cremilda entendi que a etnografia funciona justamente como um método de pesquisa comunicativo, quando a "informação" é mediada pelo primeiro mediador possível: a presença. É compartilhando a presença que podemos perceber certos detalhes que o compartilhamento de informações à distância, em geral, desprivilegia. A sugestão se aproxima da ideia de olhar para o outro com os olhos da alma - para retomar a noção de atenção em Simone Weil - que transcende a ideia de olhar como exercício da visão, enfocando uma inteligência que abrace a imaginação como metodologia (BOSI, 2003), ou, nos termos de Cremilda, rumando para uma construção de cumplicidade afetiva.

Como Roberto Da Matta (1978) fala num texto clássico seu, é preciso compreender a etnografia como momento epifânico da interpretação que decola do código linguístico e vai para além dele, dependendo também de uma etapa de vivência e de uma etapa de reflexão profunda. Para o antropólogo brasileiro, há três momentos na pesquisa: o estudo teórico (fase teórico-intelectual), a ida a campo (período prático) e a transformação (fase pessoal ou existencial) - para ele, a mais importante.

A escrita de Cremilda tem uma hipótese fundadora: o confronto direto com as realidades do mundo, isso que se chama o ato presencial, desestabiliza quaisquer explicações totais e racionalidades reducionistas. Ele convoca, obrigatoriamente, ao sutil mistério da transformação. Exercitar a autoria coletiva nos leva a pôr em xeque e atualizar constantemente nossa visão de mundo - esse processo que Da Matta chamou de fase existencial. No encontro, quando há espaço para um diálogo dos afetos, cria-se a possibilidade de transformação de ambas as partes, sem o autoritarismo de "fazer a cabeça" de ninguém, mas através da criação de cumplicidades mútuas. Esse é um mistério cuja importância precisa ser defendida como uma reserva de humanidade, uma inutilidade a ser defendida - e que, muito provavelmente, nenhum investimento em inteligência artificial seja capaz de sequer trincar a superfície.

Naquela tarde de agosto de 2016, cheia de atribulações decorrentes de uma enorme chuva e da falta de luz na faculdade, insistimos em nos fazer presentes e defender 
ferrenhamente as coisas inúteis que garantem nossa humanidade. Esse foi um grande acontecimento do ano para este pequeno grupo de estudantes atrincheirados dentro da pósgraduação, num período de manobras políticas intermitentes em Brasília, em que era difícil nos concentrarmos em qualquer outra coisa para além da incerteza do porvir. Em troca, Cremilda nos presenteou com seu mais recente livro e com sua presença.

\section{Referências}

BOSI, Ecléa. A atenção em Simone Weil. Revista Psicologia USP, São Paulo, v. 14, n. 1, p. 11 20, 2003.

DA MATTA, Roberto. 0 ofício de etnólogo, ou como ter "anthropological blues". In: NUNES, Edson de Oliveira (Org.). A aventura sociológica: objetividade, paixão, improviso e método na pesquisa social. Rio de Janeiro: Zahar Editores, 1978. p. 23-35.

MEDINA, Cremilda. Casas da viagem: de bem com a vida ou afetos do mundo. São Paulo: Ed. da autora, 2012.

MEDINA, Cremilda. Atravessagem. São Paulo: Summus, 2014.

MEDINA, Cremilda. Ato presencial: mistério e transformação. São Paulo: Casa da Serra, 2016.

ORDINE, Nuccio. A utilidade do inútil: um manifesto. Rio de Janeiro: Zahar, 2016.

RESTREPO, Luis Carlos. 0 direito à ternura. Petrópolis: Vozes, 1998.

Recebido em 18/12/2016

Aceito em 16/04/2017 